be generated by improving terms of trade along the lines proposed in the talks on General Agreement on Tariffs and Trade.

The United Nations Development Programme's Human Development Report 1992 recommends that one fifth of overseas aid budgets should go towards meeting basic needs. ${ }^{9}$ Most donors earmark about a tenth of their budgets for this, Britain earmarks $8.8 \%$. Britain also lags behind the target for overseas aid of $0.7 \%$ of gross national product set by the United Nations for donor nations. Britain, at $0.3 \%$, is not even half way there.

Of most immediate importance, however, is the removal of the millstone of debt from around the neck of developing countries. A meeting of the group of seven major industrialised countries (G7) in Toronto in 1988 agreed to write off $50 \%$ of debts, but the terms applied only to debts recently incurred by the poorest countries. In Trinidad in 1990 Britain proposed writing off up to $80 \%$ of debt, but other members of the group, including the United States, have yet to agree. Opposition parties in Britain are also proposing that debt repayments be limited to a maximum of $10 \%$ of a country's export revenue.

Public support for these measures is vital. The members of parliament attending last week's conference made it clear that little would be achieved unless concern for the plight of developing countries registered strongly in opinion polls at election time. Mobilising such concern during a recession is not easy. One approach is to show people that what happens in the Third World directly affects them. ${ }^{10}$ Third World debt holds back world economic recovery, increases the spread of disease, feeds the international traffic in drugs, damages the environment, and increases political instability and civil war, thus adding to the global refugee crisis. It also indirectly adds to the desire for arms. ${ }^{10}$ We need to recognise that security in the period after the cold war rests not in armaments but in the creation of political, economic, and social stability. Like the public health reforms of the Victorian age, action for the Third World can quite properly be justified by enlightened self interest.

The immediate role of health professionals is clearly to raise public awareness in whichever way they can. With greater public awareness might come pressure on the World Bank and the International Monetary Fund for greater accountability. The conference concluded that there should be an annual debate in parliament to examine the activities of these two agencies, which fall outside normal democratic control. They should have to justify how they spend the $£ 20$ (\$30) that they receive from each of us every year.

Third World debt is a drain on health and must be addressed. In the words of Dr Dorothy Logie, a general practitioner and a member of MedAct, "What is the point of immunising children if we are then going to starve them?"

FIONA GODLEE

Assistant editor, $B M F$

1 George S. A fate worse than debt. London: Penguin, 1990.

2 Madden P. A raw deal. London: Christian Aid, 1992.

3 World Bank. World development report 1993. Investing in health. New York: Oxford University Press, 1993.

4 Unicef. Africa's recovery in the 1990s-from stagnation and adjustment to human development. Florence: Unicef, 1992

5 Unicef. The progress of the nations 1993. New York: Unicef, 1993.

6 Unicef. Balance sheet of human progress in Africa. New York: Unicef, 1992.

Tullberg R. Military related debt in non-oil developing countries. In: Stockholm International Peace Research Institute. SIPRI yearbook 1985. London and Philadelphia: Taylor and Francis, 1985

8 Unicef. First call for children: World declaration and plan of action from the world summit for children. Convention on the rights of the child. New York: Unicef, 1990.

9 United Nations Development Programme. Human development report 1992. New York: Oxford University Press, 1992.

10 George S. The debt boomerang. London: Pluto Press, 1992.

\title{
Prostitution: would legalisation help?
}

\author{
Social and moral attitudes, rather than legal restraints, are central to the problem
}

It may be the oldest profession, but prostitution remains a thriving industry because it satisfies a demand. Although the buyer (more often male) wants to buy, the seller (more often female) is often obliged to sell sexual services because of limited economic opportunities. For some sellers this necessity is increased by a drug habit. Easy to define in theory, less so in practice, prostitution enjoys in Britain a paradoxical legal status whereby the actual transaction is legal while more peripheral aspects (including collaborating with others to provide a service and public promotion) are illegal.

Several problems exist for male and female sex workers, some due to and many exacerbated by illegality. Access to health care may be difficult, and sexually transmitted diseases have always been a risk, which HIV highlights. The risks of infection are increased by market forces, which make unsafe sex more lucrative, while the carrying of condoms is used as legal evidence of prostitution. Physical violence including rape is common, but police and legal services may be inaccessible or unsympathetic, rendering its reporting futile.

While some people cannot acknowledge that commercial sex is anything but a minority "deviant" demand, others recognise it as commonplace, with some people regarding it as a component of normal male sexual behaviour. Whatever the viewpoint, buyers from all backgrounds vastly outnumber sellers, yet if disclosure occurs the purchaser attracts sympathy for any repercussions while the provider, viewed as immoral and responsible for the prostitution, attracts censure. Thus prostitutes suffer stigmatisation and discrimination while working in inadequate conditions with poor remuneration and no employment rights or benefits.

So what would decriminalisation or legalisation of prostitution achieve? Theoretically, it should improve conditions for prostitutes in all circumstances by enabling them to work together in a more organised way, with more control over clients, services, and fees. Arguably, it would facilitate the provision of health care, while freedom to carry condoms would reduce the risk of sexually transmitted infections. The risk of physical assault would similarly be reduced by the freedom to negotiate openly with and to scrutinise potential customers without fear of legal penalties or harassment by police, who would instead provide protection from violent or sexual crimes.

But the reality would be different. Common throughout society, prostitution is particularly problematic at the lower end of the market, among women working in isolation on the streets and especially those with a drug habit. While prosecution might cease, the underlying poverty and social problems, including drug use, that led to prostitution would ensure its continuation. While the provision of health care might be improved, its inadequacy is a reflection not of 
illegality but of ineffective use of services by socially disadvantaged people and of services unsuited to their needs. Attitudes of the providers of services, real or perceived, are a further disincentive. Effective services can, however, be provided if the needs and wishes of prostitutes are acknowledged. ${ }^{1}$ Infection and violence are not confined to commercial sexual relationships, and changes in legislation would not guarantee impartial treatment by police.

Debate continues over the relative merits of decriminalisation and legalisation and, indeed, over whether specific effects might even be beneficial. Decriminalisation might seem the more limited reform, with legalisation a more radical option that would allow prostitutes to work in organised brothels as tax paying members of society. The English Collective of Prostitutes, however, argues that state controlled brothels would prove repressive with more, rather than less, exploitation of prostitutes. ${ }^{2}$ The collective also suggests that the motivation for changing the legal status of prostitution is more likely to result from concerns for the interests of those buying sexual services than from concerns for the interests of those selling them.

Prostitution will continue because a fall in demand is unlikely, but the level of prostitution might be reduced if the prostitute's need to sell sexual services was reduced. Providing alternative employment is difficult, and managing social problems, especially drug use and poverty, should be a prime objective. Prosecuting prostitutes does not reduce prostitution and in fact increases the prostitute's need to work to pay the fines imposed.

Although the precise benefits and best method of ending the illegality of prostitution may be debatable, this change is both necessary and desirable. Although the English Collective of Prostitutes believes that abolishing the relevant laws would abolish the stigma, social and moral attitudes rather than legal restraints are central to the problems of prostitution. Only when these are confronted can the problems of prostitution, legal or illegal, be resolved. Sadly, current trends in the social management of vulnerable people give little cause for optimism.

MARY HEPBURN

Royal Maternity Hospital,

Glasgow G4 0NA

Senior lecturer in women's reproductive health

1 Maclver N. Developing a service for prostitutes in Glasgow. In: Bury J, Morrison V, McLachlan S, C. Working with homen and AIDS. London: Tavistock/Routledge, 1992:85-95. 2 Lopez-Jones N. Legalising brothels. New Law fournal 1992; May 1:594-5.

\section{How safe is tamoxifen?}

\section{Only large randomised controlled trials can decide}

Tamoxifen has emerged as the main endocrine treatment for all stages of breast cancer. ${ }^{1}$ Adjuvant tamoxifen produces a survival advantage, irrespective of oestrogen receptor status, in postmenopausal women and a $40 \%$ decrease in second primary breast cancers overall. ${ }^{2}$ Associated physiological benefits of the oestrogen-like actions of tamoxifen include a fall in circulating cholesterol concentration, ${ }^{3}$ which could translate into fewer fatal myocardial infarctions ${ }^{4}$ or at least fewer admissions to hospital for cardiac conditions, ${ }^{5}$ and the maintenance of bone density in the lumbar spine. ${ }^{6}$ An estimated 4.5 million women years of experience with tamoxifen have now accrued, and treating all postmenopausal women with breast cancer with tamoxifen would save lives. ${ }^{7}$

Treating breast cancer once it has been diagnosed may not be enough, and pressures are being exerted for preventive strategies. Tamoxifen is an obvious choice because a sound laboratory rationale for its use exists ${ }^{8}$ and, for the foreseeable future, there is no prospect of an agent being developed that could provide its benefits in clinical practice. But how can the drug be evaluated?

Thirty years ago, believing that it might prevent some breast cancers, doctors might have prescribed tamoxifen to women at an increased risk, and this would have been acceptable. But times have changed, and randomised clinical trials-to protect doctors from bias and exaggerated claims by the pharmaceutical industry and patients from misguided doctors - are here to stay. They are modern medicine's most powerful tool, allowing the evaluation of efficacy and side effects without emotion.

The breast cancer prevention trial originating in the Royal Marsden Hospital continues to recruit volunteers at high risk of the disease. ${ }^{9}$ Already 2000 volunteers have been randomised, and recruitment continues despite concerns that tamoxifen causes liver tumours in rats. ${ }^{10}$ Meanwhile, the National Cancer Institute in the United States is sponsoring a prevention study with tamoxifen, and more than half of the required 16000 volunteers have been recruited. In Italy volunteers are also being randomised to a tamoxifen prevention trial that started this year; 20000 women will participate.

But fears have been raised about tamoxifen's safety. Most of the concern has focused on whether tamoxifen is a liver carcinogen. To the question "Is tamoxifen safe?" the answer must be, "Compared with what?" Tamoxifen promotes hepatic tumours in rats ${ }^{11}$ and causes the formation of adducts to DNA in rat livers. ${ }^{12}$ As oestrogens are notorious rat liver carcinogens and tamoxifen has oestrogenic properties in both rodents and humans, ${ }^{8}$ these effects are unsurprising.

A comparison with oral contraceptives is instructive here. Their oestrogen component induces tumours in rat liver, and women with at least five years' extended use are at increased risk of developing hepatocellular carcinoma. ${ }^{13}$ Objections currently being made to tamoxifen should therefore apply equally to oral contraceptives. But epidemiologists consider that the 10-fold increase in the risk of hepatocellular carcinoma with oral contraceptives is insignificant given the rarity of the tumour in Western countries ( 5 per 100000), and the convenience of avoiding pregnancy far exceeds the risk of liver cancer. In contrast, the incidence of hepatocellular carcinoma in patients treated with tamoxifen cannot be documented with any certainty: two cases have been reported in women receiving $40 \mathrm{mg} /$ day.

Reports of ocular and endometrial side effects of tamoxifen have been reviewed recently, ${ }^{14}$ but determining the true incidence of these effects outside published placebo controlled, randomised clinical trials is difficult. Women who have taken or are taking tamoxifen may develop endometrial carcinoma, but whether tamoxifen causes endometrial carcinoma or increases the rate of detection of occult disease is unknown. These risks can be quantified only in placebo controlled clinical trials.

One understandable concern is the expanded use of 